$\Phi=-1$

\title{
Barriers to Sustainable Practices towards Low Carbon Emission Projects in Malaysia
}

\author{
Mustafa M. A. Klufallah ${ }^{\mathrm{a}^{*}}$, Idris Othman ${ }^{\mathrm{b}}$, Muhd Fadhil Nuruddin ${ }^{\mathrm{c}}$, Mohd Faris Khamidi ${ }^{\mathrm{d}}$ abc Department $^{\circ}$ \\ of Civil \& Environmental Engineering, Universiti Teknologi PETRONAS, Bandar Seri Iskandar, 32610 \\ Seri Iskandar, Perak, Malaysia. \\ d Department of Built Environment, University of Reading Malaysia, Menara Kotaraya, \\ 80000, Johor Bahru, Johor, Malaysia
}

*Corresponding author E-mail: almoshli@hotmail.com

\begin{abstract}
:
The Malaysian construction industry significantly contributes as an empowerment to its development vision of 2020 by reducing up to $40 \%$ of carbon emission. Moreover, the industry accounts as threat to the environment, not only in terms of natural resources consumption but also in emitting million tons of carbon emission annually. In fact, Malaysia is categorized the 30th in the world's ranking in carbon emission level. Several studies attempt to investigate and review barriers that face construction stakeholders in order to provide integration of sustainability in construction industry. However, the barriers were lacking in terms of addressing carbon emission aspects of sustainable practice and limit the emissions from construction projects in Malaysia. This paper investigates the major barriers of organization in achieving sustainability's best practice. The identified barriers from the perspective of construction stakeholders in Malaysia were categorised based on factor analysis, which are professional and capacity, design and technologies, cost and finance, and, knowledge and culture.
\end{abstract}

Keywords: Carbon emission, Barriers, Factor analysis, Sustainabilit

\section{Introduction}

The construction industry has contributed significantly to the Malaysian economy due its extensive linkages with other industries such as the manufacturing construction and financial services industry. Furthermore, it plays a significant role to the growth of the gross domestic product (GDP). Construction, operation and demolition of building projects have a great impact on the environment directly (through material and energy consumption and the associated pollution and waste) and indirectly (through the pressures on often inadequate infrastructure).

It has been observed that the rate of carbon emission in the Earth's atmosphere has raised slightly from the rate that was measured at the beginning of the century. Carbon dioxide $\left(\mathrm{CO}_{2}\right)$ concentrations can be controlled during

production and manufacturing of materials throughout assessment procedures, which involve direct and indirect carbon emissions (Dixit et al., 2010). In the member states of the European Union, buildings throughout the life cycle, including construction, operation and demolition, consume approximately $50 \%$ of the total energy demand and contribute almost $50 \%$ of the carbon emission released to the atmosphere (Yan et al., 2010). In Malaysia, buildings account for about $20 \%$ of the production of greenhouse gases (GHG) that coming in third after transportation and other industries (Abdul Samad et al., 2008).
Although sustainability is important for the development of countries, but still there are barriers that prevent this practice in many countries including Malaysia. Several studies around the world attempt to investigate and review these barriers in order to provide integration of sustainability in construction industry.

These barriers have real or perceived impacts on the risk and profit of various industry groups and may therefore influence their decision. Barriers investigation would lead to determine essential solutions, promote of sustainable development and attract organization to implement this concept. In order to endorse and drive the agenda of sustainable construction within the Malaysian construction industry, the barriers that impede these practices must first be investigated.

\section{Literature Review}

In Malaysia, there is a wide gap of knowledge and awareness on sustainable building practices and stakeholders mainly consider economic issues rather than taking a balanced approach to economic, environmental and social sustainability (Shari \& Soebarto, 2013). The greatest barrier to achieve sustainable buildings in the South-East Asian construction industry is the lack of understanding of the need for sustainable design due to the lack of awareness among stakeholders (Shafii \& Othman, 2007). 
lack of database (case studies) and lack of strategy to promote green buildings (Samari et al., 2013). Moreover, people issues (i.e. lack of management commitment), strategic issues (i.e. resources, performance measurement,

financial, technical, information, managerial and organizational, etc.), Functional issues (purchasing and supply function, lack of corporate structures and processes) are also considered barriers to sustainable practice (Tay et al, 2015).

It can be concluded that the progress to develop the culture of sustainability among local building stakeholders in Malaysia is rather slow (Shari \& Soebarto, 2013). Although concerns for sustainability are now embedded in many government policies and initiatives, they are still not integrated into the Malaysian property development and investment practices (Shari \& Soebarto, 2013). In general, the main barriers to the development of green buildings in Malaysia from the available accessible literature were summarized as shown in Figure 1 (Samari et al., 2013).

The barriers were lacking in terms of addressing the carbon emission aspects of sustainable practice and to limit the emissions specifically from office construction in Malaysia. Therefore, one of the research question is "what are the major barriers to sustainable building and assessment of carbon emission management in Malaysia?".

\section{Method of Research}

The questionnaire survey was used to determine and rank the factors that limit the implementation of sustainable practices among construction stakeholders in Malaysia. However, from the accessible published studies, there has not been a prior study determined the barriers

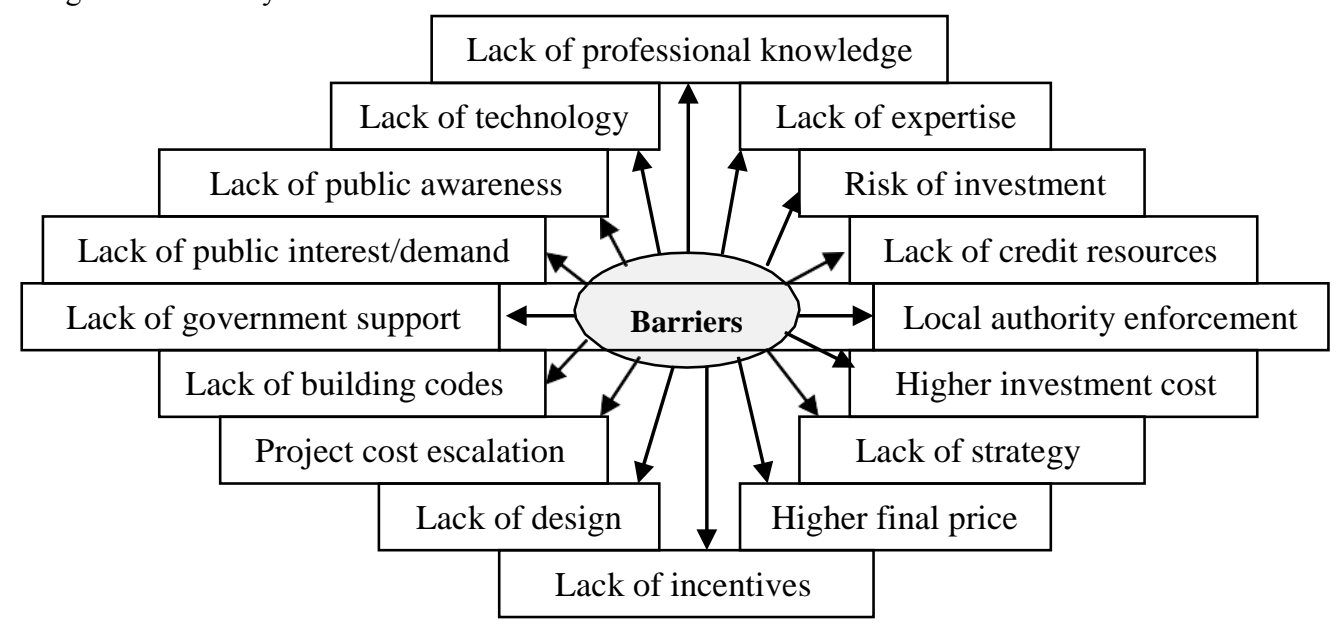

Figure 1. Barriers to sustainable practice (Samari et al., 2013)

with regards to carbon emission from office buildings in Malaysia. Nevertheless, this is not to say that the measurement of sustainability barriers have not been measured in the past. The method adopted for this study was based on a structured questionnaire survey of four principal target groups within the Malaysian construction industry, focusing on the states of Selangor and Kuala Lumpur in Malaysia. The targeted groups, representing a mixture of professionals, including those dealing with policy formulation, design, construction, quantity surveying, and clients of construction projects. It is also important that such a population gives a true representation of the construction organizations.

A total of 500 questionnaires were sent out to the different selected groups in the Malaysian construction organizations. The 110 questionnaires were returned, making the total response rate of $22.0 \%$. This response rate is not uncommon and acceptable and it is in line with the opinions of Akintoye (Akintoye, 2000). They reported that the norm response rate in the construction industry for postal questionnaires is around 20-30\%. Statistical Packages for Social Sciences (SPSS) was used to analyze the data quantitatively.

\section{Analysis and Discussion}

\section{Profile of Respondents}

There were 60 developers respondents, making up about 54.55 percent of the total respondents of 110 , there were 29 consultants respondents which is the second highest portion of the respondents making up about 26.4 percent, another fifteen (15) respondents were contractors and represent $13.64 \%$ percent.

Sixty (60) (54.55\%) respondents were from the government public developers, followed by $29(26.36 \%)$ from consultant organization, $15 \quad(13.64 \%) \quad$ from contractors companies, and $6(5.45 \%)$ from others types of companies.

\section{Test of Normality}

The histogram in Figure 2 is skewed to right which indicates that the distribution is not normal. The histogram shows a concentration of the frequencies to the right with fewer frequencies to the left.. From the above analysis for test of normality, non-parametric tests would have to be used since the distribution of data violates all assumptions of normality 


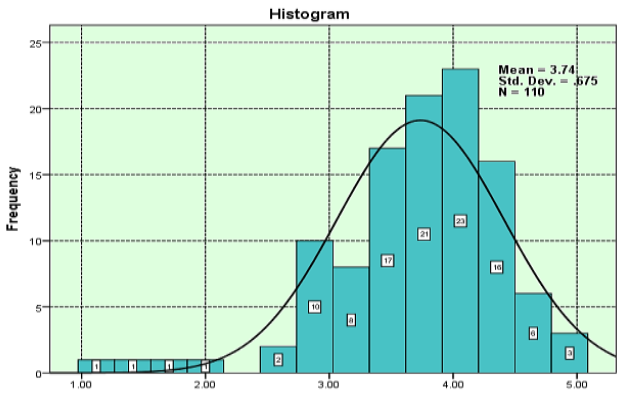

Figure 2. Histogram of frequencies

\section{Factor Analysis}

From the result in Table 1, it can be seen that the KMO is very high with a value of 0.882 , the KMO values range from $0-1$ and the closer to one the better for a good factor analysis, and the Bartlett's test of Sphericity was significant at $\mathrm{p}<.001$ confirming the factorability of the data. After achieving the factorability of the data, it is essential to identify how many factors that can be extracted from the data set. The method used was the absolute magnitude of the eigenvalues of factors

Table 1. Keiser-Meyer-Olkin and Bartlett's test of sphericity

\begin{tabular}{|c|c|c|}
\hline 1. Kaiser-Meyer-Olkin Measure of Sampling Adequacy. & & .882 \\
\hline & Approx. Chi-Square & 1251.352 \\
\hline & $\mathrm{df}$ & 136 \\
\hline 2. Bartlett's Test of Sphericity & Sig. (p) & .000 \\
\hline
\end{tabular}

(eigenvalues-greater-than-one-criteria). The initial four factors were further confirmed by the total variance explained in Table 2. The first factors accounted for $21.69 \%$ of the variance, the second factor accounted for $20.12 \%$ and the third factor accounted for $17.37 \%$ while the fourth accounted for $12.22 \%$. The extraction method employed was the principal component analysis while the rotation method was Varimax rotation method with Kaiser Normalization and the rotation converged in 6 iterations as shown in Table 3 practices and reducing the carbon emissions from their projects. The factors were named based on the factors using the underlying thematic connections among the items as follows:

Profession and capacity.

Designs and technologies.

Cost and finance.

Knowledge and culture.

The results indicated that professional and capacity is one of the most critical barriers to sustainable construction in order to practice

Table 2. Total Variance Explained

\begin{tabular}{|c|c|c|c|c|c|c|c|c|c|}
\hline \multirow[b]{2}{*}{ No } & \multicolumn{3}{|c|}{ Initial Eigenvalues } & \multicolumn{3}{|c|}{ Extraction Sums } & \multicolumn{3}{|c|}{ Rotation Sums } \\
\hline & Total & $\begin{array}{c}\% \text { of } \\
\text { Variance }\end{array}$ & $\begin{array}{c}\text { Cumulative } \\
\%\end{array}$ & Total & $\begin{array}{c}\% \text { of } \\
\text { Variance }\end{array}$ & $\begin{array}{c}\text { Cumulative } \\
\%\end{array}$ & Total & $\%$ of Variance & $\begin{array}{c}\text { Cumulative } \\
\%\end{array}$ \\
\hline 1 & 8.442 & 49.662 & 49.662 & 8.442 & 49.662 & 49.662 & 3.687 & 21.691 & 21.691 \\
\hline 2 & 1.632 & 9.600 & 59.262 & 1.632 & 9.600 & 59.262 & 3.421 & 20.123 & 41.814 \\
\hline 3 & 1.161 & 6.832 & 66.094 & 1.161 & 6.832 & 66.094 & 2.954 & 17.377 & 59.191 \\
\hline 4 & .904 & 5.320 & 71.414 & .904 & 5.320 & 71.414 & 2.078 & 12.224 & 71.414 \\
\hline 16 & .148 & .872 & 99.395 & & & & & & \\
\hline 17 & .103 & .605 & 100.000 & & & & & & \\
\hline
\end{tabular}

Table 3. Rotated component matrix for construction's stakeholders

\begin{tabular}{|c|c|c|c|c|c|}
\hline No & Factors & 1 & 2 & 3 & 4 \\
\hline 1 & Inadequate access to international experts & .844 & & & \\
\hline 2 & Inadequate access to employees' training & .781 & & & \\
\hline 3 & Difficulties in payment for internationals experts & .705 & & & \\
\hline 4 & Lack of top management towards green technologies & .686 & & & \\
\hline 5 & Lack of market information & .638 & & & \\
\hline 6 & Inadequate access to customers' demand & .534 & & & \\
\hline 7 & Lack of familiarity of low $\mathrm{CO}_{2}$ designs & & .798 & & \\
\hline 8 & Unclear understanding of the environmental issues & & .755 & & \\
\hline 9 & Absence of project emission data & & .704 & & \\
\hline 10 & Change from traditional designs to green designs & & 697 & & \\
\hline 11 & Inadequate access to green technologies & & 607 & & \\
\hline 12 & Difficulties in allocating financial resources & & & .842 & \\
\hline 13 & Lack of capital for achieving green projects & & & .798 & \\
\hline 14 & High cost of low $\mathrm{CO}_{2}$ emission projects & & & .773 & \\
\hline 15 & Unclear cost solutions of green designs & & & .547 & \\
\hline 16 & Unclear understanding of project emissions & & & & .846 \\
\hline 17 & Lack of $\mathrm{CO}_{2}$ reduction requirements & & & & .841 \\
\hline
\end{tabular}

The four extracted factors were the essential barriers for the constructions' stakeholder regarding the implementation of gree and implement sustainable practices. Furthermore, it has been reported that sustainability awareness and lack of common 
understanding by professional in construction industry towards sustainable buildings is low and professionals need to be fully aware about the principles of sustainable construction in order to implement sustainability practices successfully within the built environment (Djokoto, Dadzie, \& Ohemeng-Ababio, 2014). Lack of market information about products is one of the main factors that can increase the demand of green buildings. Introducing available and accessible information to the Malaysian construction industry with regards to informative database related to product's emission for essential factor. sustainable practice to stakeholders is

\section{Conclusion}

The need to involve professionals who are not only knowledgeable but can work as a team to promote sustainable construction with training programs in addressing the current and future environmental concerns within the construction industry is essential in promoting sustainable development. Another barrier that faced by the construction stakeholders is the construction cost and finance factor for constructing green buildings.

This paper identifies barriers to sustainable construction in the Malaysian construction industry. Consequently, this paper has identified four major barriers to sustainable construction encountered as professional and capacity, design and technologies to promote sustainable construction, higher cost and financial and knowledge and culture. In line with this, an improvement of skills in this sector is required. This suggests that there is a need for policy and regulations on green issues, which may be achieved by the initiatives promoted by government.

\section{Acknowledgements}

The authors wish to thank the Universiti Teknologi PETRONAS (UTP) for providing the facilities and financial support.

\section{References}

[1] Abdul Samad, MH, Abdul Rahman, AM, \& Ibrahim, F. (2008). Green Performance Ratings for Malaysian Buildings with Particular References to Hotel. (1CERT 2008), Environment Technology and Management.

[2] Akintoye, Akintola. (2000). Analysis of factors influencing project cost estimating practice. Construction Management \& Economics, 18(1), 77-89

[3] Dixit, Manish Kumar, Fernández-Solís, José L., Lavy, Sarel, \& Culp, Charles H. (2010). Identification of parameters for embodied energy measurement: A literature review. Energy and Buildings, 42(8), 1238-1247.

[4] Djokoto, Susan Dzifa, Dadzie, John, \& Ohemeng-Ababio, Eric. (2014). Barriers to sustainable construction in the Ghanaian Construction Industry: consultants perspectives. Journal of Sustainable Development, 7(1), 134.

[5] Samari, Milad, Ghodrati, Nariman, Esmaeilifar, Reza, Olfat, Parnaz, \& Shafiei, Mohd Wira Mohd. (2013). The investigation of the barriers in developing green building in Malaysia. Modern Applied Science, 7(2), 1

[6] Shafii, F, \& Othman, MZ. (2007). Sustainable buildings in South-East Asia: Opportunities and implementation. Paper

Corresponding Author: Mustafa Klufallah, Department of Civil \& Environmental Engineering, Universiti Teknologi PETRONAS, 32610 Seri Iskandar, Perak, Malaysia

E-mail: almoshli@hotmail.com presented at the Conference on Sustainable Building South-East Asia (SB07). Kuala Lumpur, Malaysia.

17] Shari, Zalina, \& Soebarto, Veronica. (2013). Investigating sustainable practices in the Malaysian office building developments. Construction Innovation, 14(1), 17-37.

[8] Tay, Mee Yean, Rahman, Azmawani Abd, Aziz, Yuhanis Abdul, \& Sidek, Shafie. (2015). A Review on Drivers and Barriers towards Sustainable Supply Chain Practices. International Journal of Social Science and Humanity, 5(10), 892.

[9] Yan, Hui, Shen, Qiping, Fan, Linda $\mathrm{CH}$, Wang, Yaowu, \& Zhang, Lei. (2010). Greenhouse gas emissions in building construction: A case study of One Peking in Hong Kong. Building and Environment, 45(4), 949-955 